\title{
LINEAMIENTOS PARA UN PLAN DE GESTIÓN INTEGRAL EN EL MANEJO SOSTENIBLE, ADMINISTRACIÓN Y PROTECCIÓN DEL RECURSO HÍDRICO, EN EL ESPACIO COSTERO EL COCO, PENÍNSULA DE NICOYA, COSTA RICA
}

\author{
GUIDELINES FOR A COMPREHENSIVE PLAN ON \\ SUSTAINABLE MANAGEMENT , MANAGEMENT AND \\ PROTECTION OF WATER RESOURCES, COASTAL \\ SPACE IN EL COCO, NICOYA PENINSULA, COSTA RICA
}

\author{
Lidia Orias-Arguedas ${ }^{1}$ \\ Universidad Nacional, Costa Rica
}

\section{RESUMEN}

El presente documento constituye la continuación del artículo denominado: La expansión del espacio costero El Coco y su relación con la vulnerabilidad a la contaminación del recurso hídrico, Península de Nicoya, Costa Rica, presentado en la Revista Geográfica de América Central, Número $\mathrm{N}^{\mathrm{o}}$ 50, I Semestre 2013. Se problematiza las condiciones del recurso hídrico en el espacio costero El Coco, según factores, categorías, indicadores de impacto, rangos de vulnerabilidad y actores involucrados en toma de decisiones para la gestión. La propuesta articula en la figura de un Plan de gestión integral en el manejo sostenible, administración y protección del recurso hídrico, dos programas con directrices y estrategias. El primero, referente al manejo sostenible, sistemas de control y gestión administrativa del recurso hídrico y el segundo programa, desarrolla la importancia

1 Pertenece a la Escuela de Ciencias Geográficas, Universidad Nacional, Heredia, Costa Rica. Correo electrónico: lidiaoria@gmail.com 
Lidia Orias-Arguedas. Guidelines for a comprehensive plan on sustainable management, management and protection of water resources, coastal space in El Coco, Nicoya Peninsula, Costa Rica

de un proyecto que permita la reforma de la legislación en materia del recurso hídrico en espacios costeros y la gestión institucional pública.

Palabras clave: Plan de gestión integral del recurso hídrico, Espacio urbano costero, acuífero El Coco, Expansión urbana, gobernabilidad del recurso hídrico, Ordenamiento del territorio

\begin{abstract}
This document is the continuation of the article entitled: "The Expansion of El Coco Coastal Urban Space and Its Relationship with Vulnerability to Pollution of Water Resources, Nicoya Peninsula, Costa Rica," included in the Central American Geographic Magazine, Issue No.50, I Semester 2013. The conditions of water resources in El Coco urban coastal space are questioned depending on factors, categories, impact indicators, vulnerability ranges, and those involved in the decision-making process. The proposal seeks to articulate, in the figure of a Comprehensive Plan of Water Resources Management, two programs with guidelines and strategies. The first one refers to sustainable management, control systems, and administrative management of water resources. The second program refers to the importance of developing a project to amend the legislation on water resources in coastal areas and public institutional management.
\end{abstract}

Keywords: Plan comprehensive water resource management, coastal urban space, aquifer El Coco, Urban Sprawl, governance of water resources, land use planning.

\title{
Introducción
}

La presente investigación se realizó en el espacio urbano costero El Coco, del distrito Sardinal del cantón de Carrillo, de la Península de Nicoya.

El área de estudio se asienta sobre el acuífero El Coco, que presenta un acelerado crecimiento urbano, enfocado en la actividad turística, que ha incrementado la presión por el recurso hídrico, debido a los cambios en el uso de la tierra, por el aumento de actividades económicas, que paralelamente han favorecido la extracción de agua de pozos privados sin regulación. Esta realidad ha provocado una alta vulnerabilidad a la contaminación del acuífero costero El Coco.

No existen investigaciones antecedentes en el espacio costero El Coco, ni en otros distritos del cantón de Carrillo, referentes a planes de Gestión integral del recurso hídrico, en el manejo sostenible, administración y protección, que considere el conjunto de factores de vulnerabilidad a la contaminación del cuifero y sus posibles impactos negativos en los entornos naturales como en los humanos.

Se propone un Plan de gestión integral en el manejo sostenible, administración y protección del recurso hídrico, considerando las políticas, la legislación, las normativas nacionales y las directrices de los actores locales. 
Para la elaboración del Plan de getión integral, se utilizaron fuentes secundarias para realizar un análisis de las características geológicas e hidrogeológicas del área de estudio; asimismo, para efectuar un análisis histórico del uso de la tierra, a fin de investigar el proceso de construcción y transformación del espacio costero. Se utilizaron como fuentes primarias: 60 encuestas estructuradas, dirigidas a usuarios del servicio de agua potable y cinco entrevistas abiertas a dirigentes locales (tres) y actores procesionales (dos), para obtener información acerca del uso y la gestión del agua.

\section{Delimitación y caracterización física del área de estudio}

Territorialmente, el espacio costero El Coco, forma parte del distrito Sardinal del cantón de Carrillo, en la Península de Nicoya, Guanacaste. Representa una extensión de 21, $49 \mathrm{~km}^{2}$, con un perímetro de 27,75 Km.

Se localiza, según el Sistema de Proyección CRTM05 para Costa Rica, en las coordenadas: 1164000-1170000m.N. y 310000-317000m.E., de la Hoja topográfica Carrillo Norte, escala 1:50 000 del Instituto Geográfico Nacional (IGN).

En el área de estudio se halla dos formaciones geomorfológicas importantes de origen denudacional y aluvial:

1. La formación de origen denudacional está asociada a la presencia de los basaltos de los cerros del Complejo de Nicoya, y constituyen la mayor parte del área de estudio, con 13,12 $\mathrm{Km}^{2}$. Las máximas altitudes varían entre los 250 y 300 m.s.n.m.

2. La formación aluvial, constituida por los depósitos cuaternarios, originada por la erosión de materiales rocosos de los cerros del Complejo de Nicoya, que han sido transportados por las quebradas y depositadas en áreas de baja elevación. Los coluvio-aluviales no alcanzan alturas mayores a 50 m.s.n.m. y cubren un área de $8,37 \mathrm{Km}^{2}$.

El mapa 1, muestra el área de estudio y su expansión urbana. 
Lidia Orias-Arguedas. Guidelines for a comprehensive plan on sustainable management, management and protection of water resources, coastal space in El Coco, Nicoya Peninsula, Costa Rica

Mapa 1. Localización del área de estudio

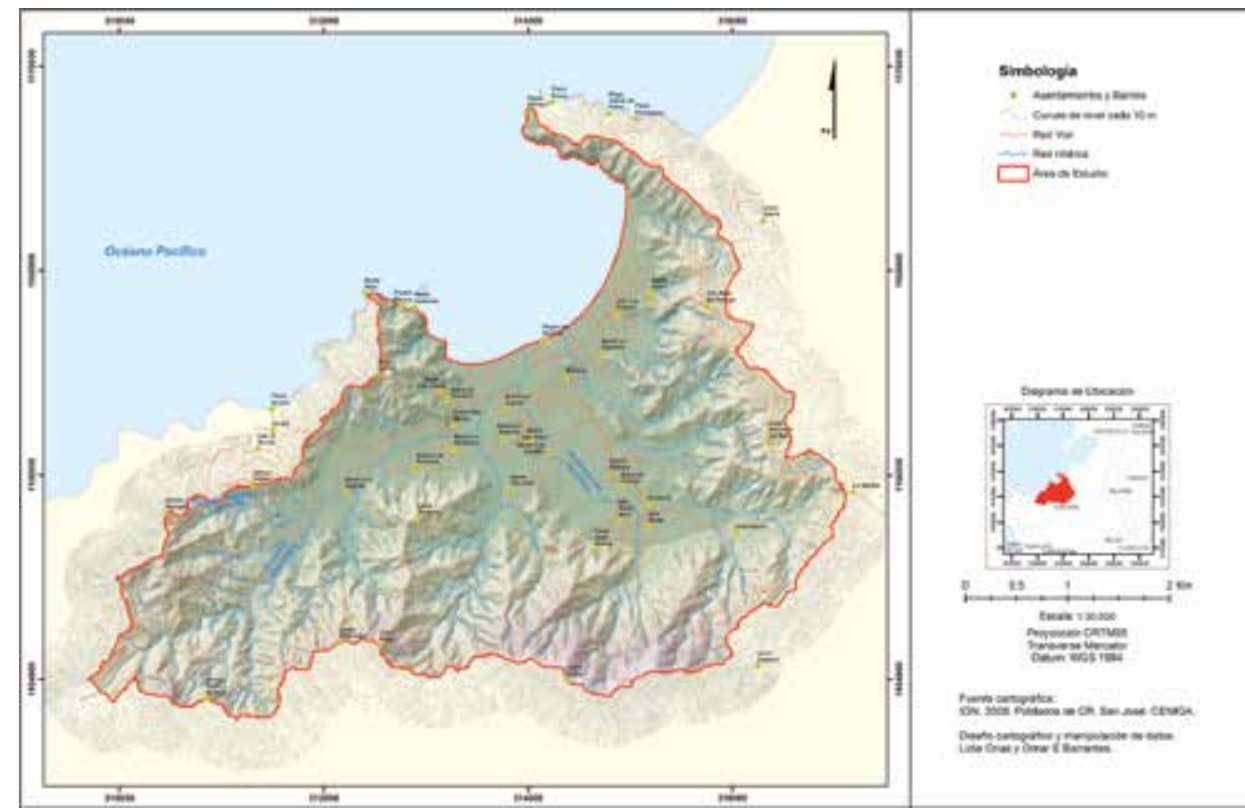

\section{Metodología}

Para proponer un PGRI en el espacio costero El Coco, durante el transcurso de la investigación, se creó un marco de referencia utilizando los siguientes principios orientadores y aplicables a otras áreas costeras de Costa Rica:

a. Un enfoque holístico para el estudio del entorno de los recursos hídricos, su ambiente natural y antrópico.

b. El reconocimiento de los diversos actores institucionales tanto públicos como privados, involucrados en los factores de vulnerabilidad e impacto a largo plazo.

c. Usos múltiples y diferenciados del recurso hídrico, por los usuarios del área costera y del litoral.

d. El coste social de los impactos negativos en los recursos y el entorno hidrogeológico.

e. Concertación y participación de actores de las instituciones vinculantes del Estado y de la sociedad civil, en las decisiones y formulación 
de la política en materia de manejo sostenible, administración y protección del recurso hídrico en El Coco.

f. La formulación de posibles estrategias que permitan la implementación de una política en materia del recurso hídrico en el espacio urbano costero El Coco, que dé base de viabilidad y factibilidad ambiental, económica - social y política - institucional.

g. La formulación de un marco de política en materia del recurso hídrico en áreas costeras a nivel interinstitucional e inter organizacional que contemple: el manejo sostenible, la administración, la restauración y la protección integral.

\section{Antecedentes}

Los procesos de expansión territorial urbana aumentaron en el área de estudio, a partir del ingreso del turismo de carácter transnacional, a partir de los años 90 del siglo pasado. Dieron como resultado el desplazamiento de los antiguos colonos de sus tierras. Un proceso de urbanismo no planificado, ni regulado por los entes públicos, provocó la coexistencia de áreas de crecimientos difusos entre viviendas y residenciales (en sus múltiples variantes), se presenta por ejemplo: la combinación de condominios lujosos amurallados frente a asentamientos en condiciones de pobreza; entre otros factores, que marcan el contexto de la construcción social del espacio urbano costero El Coco.

En la organización espacial del espacio costero El Coco, la Municipalidad de Carrillo tuvo ingerencia directa, entre otras formas, a través de permisos de construcción, en los que no se respetó al menos la Ley de Planificación Urbana 4240 (1968); asimismo, en favor de inversionistas foráneos, prueba de los esbozado, es que el 12 de octubre de 2007, desalojó 50 familias a razón de hacer cumplir la Ley de la Zona Marítima Terrestre $\left(\mathrm{N}^{\circ} 6043\right.$ del 2 de marzo de 1977). Paradójicamente, el municipio estableció nuevos usos de la tierra, fundamentalmente, para la creación de complejos hoteleros o bienes inmuebles (mercado inmobiliario), infraestructura de servicios y comercio, que hoy contaminan los esteros con residuos sólidos y aguas negras. El Laboratorio Nacional de Aguas de AyA, indicaba que hasta el 2011 Playas del Coco era una de las nueve más contaminadas del país; pero que aún eran de buena calidad entre $>10-100$ (AyA, 2012). La misma institución en otro estudio realizado entre el 2011 - 2012, advierte que el 70\% de la contaminación del mar 
Lidia Orias-Arguedas. Guidelines for a comprehensive plan on sustainable

management, management and protection of water resources, coastal space in

El Coco, Nicoya Peninsula, Costa Rica

proviene de sus dos esteros, en el estero norte se encontraron hasta 240.000 coliformes fecales por cada 100 mililitros de agua, el mínimo encontrado fue de 9.100 y en el estero sur, la cantidad de coliformes se duplicó, al registrar un máximo de 450.000 por cada 100 mililitros de agua, siendo el máximo permitido de 1.000 coliformes, esta situación ha generado a su vez, la continua muerte masiva de peces. (La Nación, 2013).

Aún con la afectación directa de la crisis económica global (desde el año 2009), en el área de estudio, el precio de la tierra se mantiene con valores muy elevados y la especulación sobre ésta se mantiene casi detenida, lo que ha generado mayor cantidad de terrenos ociosos (lotes) que han pasado a ser tierras de reserva, para la especulación en el mercado inmobiliario de carácter urbano. Aunque las condicionantes mencionadas se mantienen, continúan las actividades económicas como las inversiones del sector turístico, que paralelamente favorecen el incremento en la extracción de agua de los pozos costeros, que a su vez podrían contaminarse por intrusión salina; es así, que existe una alta vulnerabilidad a la contaminación en el acuífero de El Coco.

En el espacio costero El Coco, se presenta una escasa inversión infraestructural, que no permita la distribución y cantidad continua del agua durante todo el año, la cual es extraída a partir de energía eléctrica de cuatro pozos bombeados por el Instituto Costarricense de Acueductos y Alcantarillados (AyA). Esta situación provocó que en mayo del 2007, un grupo de inversionistas privados denominado Coco Water S.A. se uniese al suscribir el Fideicomiso para la ampliación del acueducto SardinalCoco-Ocotal, para construir un acueducto con el aval de AyA, que una vez construido sería traspasado a la institución para que le diese supervisión y mantenimiento a la obra, y amparados en los artículos 38 y 39 de la Ley de Planificación Urbana 4240. Este convenio se realizó sin el pago de impuestos a la Municipalidad de Carrillo.

El acueducto llevaría 167 litros de agua por segundo (1/s) del acuífero de Sardinal hacia el espacio costero El Coco, a partir de la perforación de cuatro pozos, AyA (2008). Este proyecto fue ratificado por el AyA sin un Estudio de Impacto Ambiental avalado por la Secretaria Técnica Nacional Ambiental (SETENA). El costo de este trasvase sería de ocho millones de dólares, cubiertos por los integrantes del fideicomiso, y serían recuperados con la venta de conexiones de agua (pajas). 
El fideicomiso crearía entre ocho a diez mil pajas de agua para proyectos urbanísticos, comerciales y turísticos, que debían pagar al fideicomiso el costo por conexión, el cual rondaría los $\$ 2.800$, más cargas financieras, equivalente a $\notin 1.500 .000$ por conexión. Para el servicio en viviendas no tendría que pagarse este monto, solo la conexión que cobrase el AyA.

La situación expuesta demuestra que la presión por el recurso hídrico se vería aumentada, toda vez que se abriesen nuevas pajas de agua, siendo el acuífero Sardinal quien aportaría el agua.

A partir de la crónica descrita, en mayo del 2008 un grupo de vecinos del distrito Sardinal se cohesionó con otros actores sociales, tomando el nombre de Confraternidad Guanacasteca. Estos llevaron el caso a la Defensoría de los Habitantes y posteriormente a la Sala Constitucional (Poder Judicial), aduciendo que el proyecto no tenía los estudios técnicos que garantizasen que el agua alcanzaría para suplir las necesidades futuras de la población, en tanto sería mayoritariamente consumida por las empresas turísticas de El Coco y por violación al artículo nueve de la Constitución Política. La Sala Constitucional falló a favor de la Confraternidad Guanacasteca en enero del 2009, declaró con lugar que:

Por violación a lo establecido en el artículo 50 de la Constitución Política, en la aprobación y puesta en ejecución del proyecto de ampliación del acueducto El Coco-Ocotal; al no existir certeza técnica sobre la capacidad de explotación del recurso hídrico del Acuífero Sardinal y la consecuente incertidumbre sobre la afectación de la prioridad de disponibilidad de agua para la satisfacción de los intereses de la comunidad, sobre cualquier otro tipo de interés patrimonial, comercial o turístico.

Por violación al artículo 9 de la Constitución Política, al omitirse la debida participación ciudadana en el proceso de formulación del proyecto.

Condena al Estado y al Instituto Costarricense de Acueductos y Alcantarillados al pago de las costas, daños y perjuicios causados con los hechos que sirven de base a esta declaratoria, los que se liquidarán en ejecución de sentencia de lo contencioso administrativo. (Sala Constitucional, Voto 626, 2009)

Paradójicamente el AyA elaboró un informe final del Proyecto "Acueducto de Playas del Coco-Ocotal", enfocado en aumentar la capacidad de producción y de almacenamiento del acueducto, y construir nueva infraestructura, que incluyese tanques de almacenamiento, sistemas 
Lidia Orias-Arguedas. Guidelines for a comprehensive plan on sustainable

management, management and protection of water resources, coastal space in

El Coco, Nicoya Peninsula, Costa Rica

de bombeo, red de impulsión y distribución. En este informe, se propone aumentar la actual capacidad del campo de tres pozos, correspondiente a 48,7 1/s. a 67,8 1/s., con la creación de tres nuevos pozos. De acuerdo con el estudio, la capacidad del acueducto, El Coco es de 49,1 1/s, el cual abastecía para el año 2006 a unos 8491 habitantes, con el proyecto del Acueducto de El Coco-Ocotal se estima aumentar la capacidad del acueducto en un $493 \%$, con una producción de 242,8 1/s para el abastecimiento de 41902 habitantes según la demanda proyectada al 2010, y que para cubrir la demanda futura sería necesario buscar nuevas fuentes de abastecimiento (Vargas, 2006).

El Servicio Nacional de Aguas Subterráneas, Riego y Avenamiento (SENARA, 2008) en su área de Aguas Subterráneas y en revisión y análisis del informe mencionado a solicitud del AyA y la Defensoría de los habitantes, propone aumentar el caudal en 19,1 1/s; sin embargo, no avala el informe y solicita:

- Un estudio hidrogeológico detallado en los acuíferos El Coco, Sardinal y Ocotal

- Una evaluación del efecto de explotación de los campos de pozos El Coco y Sardinal

- Una evaluación del riesgo de afectación a la calidad y cantidad del recurso hídrico en los acuíferos El Coco y Ocotal (SENARA, 2008, p. 6)

La gestión integral del recurso hídrico ha sido desatendida, no solo por las instituciones estatales, sino también por el gobierno local (municipal), en tanto no han creado planes de ordenamiento del territorio, enfocados en esta.

Entre los impedimentos a la gestión del recurso hídrico en el espacio urbano costero El Coco, se destaca la escasa participación de la Municipalidad de Carrillo para la búsqueda de recursos, a fin de ejecutar medidas de protección ambiental, e inversión para la colecta, disposición y tratamiento de desechos sólidos y de aguas servidas por el municipio.

En 2010, se inicia la elaboración del Plan Regulador Costero del Cantón de Carrillo, durante el proceso se presentaron diferencias entre el equipo consultor y la organización ambientalista Confraternidad Guanacasteca por el incumplimiento en la metodología establecida por el Instituto 
Nacional de Vivienda y Urbanismo (INVU, Manual de procedimientos para la redacción y elaboración de Planes Reguladores, 2007) y SETENA (Procedimiento técnico para la introducción de la Variable Ambiental en los Planes Reguladores u otra planificación de uso del suelo, 2006).

La organización ambientalista Confraternidad Guanacasteca adujo que el Plan Regulador beneficia a los hoteles del área costera, permitiéndoles concesiones en zonas por ley restringidas. El Plan Regulador Costero fue publicado en La Gaceta $N^{\circ} 173$ del 07 de setiembre de 2012; pero se objetó por estimarlo contrario a los artículos 7, 9, 50 y 89 de la Constitución Política.

La Sala Constitucional ordenó paralizar todos los trámites para poner en práctica el Plan Regulador Costero, al acoger una Acción de Inconstitucionalidad contra ese documento, por la posible violación a la legislación ambiental nacional, convenios internacionales y por la falta de consulta a la población.

Finalmente, se revela que la propuesta de Plan Regulador Costero no respeta los convenios internacionales, tendientes a proteger la biodiversidad, tales como las Leyes 7906, denominada Convención Interamericana para la Protección y Conservación de las Tortugas Marinas del 24 de setiembre de 1999 y la Ley No 3763, llamada Convención para la Protección de la Flora, la Fauna y de las Bellezas Escénicas Naturales de los países de América.

\section{Marco conceptual}

Una propuesta de Plan de gestión integral en el manejo sostenible, administración y protección del recurso hídrico, debe responder a una estrategia de desarrollo, manejo y sostenibilidad, estableciendo un proceso amplio y continuo de participación de los actores vinculados a los conflictos, uso y explotación del agua subterránea, definiendo objetivos, acciones, políticas y normativas restrictivas necesarias para alcanzar un modo de convivencia económica, social e institucional compatible con la aptitud ambiental y el patrimonio natural del agua.

Hoy la gestión integral del recurso hídrico es un tema recurrente y rebuscado, incluso por los organismos económicos y políticos, casi todos coinciden en su sostenibilidad, concepto que por sí mismo continúa en debate. Al respecto, el epílogo del Informe de las Naciones Unidas sobre el desarrollo de los recursos hídricos en el mundo del Programa de Evaluación Mundial del Agua (2003), manifiesta que: "la crisis del agua es una crisis de gestión de los asuntos públicos [...] el sector hídrico sigue 
Lidia Orias-Arguedas. Guidelines for a comprehensive plan on sustainable

management, management and protection of water resources, coastal space in

El Coco, Nicoya Peninsula, Costa Rica

contando con una financiación insuficiente [...] Llana y simplemente, no se está logrando el desarrollo sostenible" (p.2).

Según Dourojeanni (1993), el desarrollo sostenible involucra el crecimiento económico, la equidad social y la sustentabilidad ambiental; asimismo, debe concertar qué intercambios son prioritarios entre estos tres objetivos en una determinada región y entre regiones; facilitar el conocimiento, por parte de los actores involucrados, del tipo de intercambios viables y de su valor; y determinar en qué momento se alcanza el equilibrio dinámico correspondiente al desarrollo sostenible.

El PNUMA - DHI, 2009, lo concibe como un proceso que promueve la gestión y el desarrollo coordinados del agua, el suelo y los otros recursos relacionados, con el fin de maximizar los resultados económicos y el bienestar social de forma equitativa sin comprometer la sostenibilidad de los ecosistemas vitales.

Las posturas anteriores, presentan trasfondos de carácter neoliberal y crean confusión, en ellos se concibe el desarrollo sostenible conexo a temas de carácter económico, financiación y crecimiento económico, al tiempo que se introduce el concepto de equidad, que es cualitativo y representa la justa disponibilidad del recurso hídrico de acuerdo con las necesidades de las poblaciones, sobre todo de aquellas en condiciones de pobreza y vulnerables, que poco pueden incidir en la gestión del recurso hídrico que realizan las entidades públicas

En la Conferencia Internacional del Agua y el Medio Ambiente, Dublín, 1992, se redactó el Principio 4: "El agua tiene un valor económico en todos sus usos competitivos. Debe ser reconocida como un bien económico y además como un bien social.

El tema de reconocerlo como un valor económico y competitivo, crea ambigüedad porque en países subdesarrollados como Costa Rica y específicamente en espacios costeros urbanos como El Coco, es frecuente que el valor y el precio sean confundidos adrede. Grandes y reconocidos organismos internacionales se encargan de difundir esta idea, con el propósito de impulsar directrices que puedan ser seguidas por gobiernos con problemas en la distribución de agua.

En el IV Foro Mundial del Agua (2012), se introdujo el término la buena "gobernanza del agua", lo cual significa que se aplica cuando las instituciones públicas encargadas del recurso hídrico establecen una política 
efectiva, junto a un marco legal regulatorio y gestionario del agua, que responda a las necesidades ambientales, económicas, sociales y políticas del Estado, con la participación de todos los agentes sociales. En este sentido debe procurarse que la "gobernanza" también entendida como un bien demanial al que todos los seres humanos tienen derecho, no sea apropiada por agentes privados, como ocurre en países pobres como Costa Rica, a partir de la concesión por Acueductos y Alcantarillados (AyA), de Asociaciones Administradoras de los Sistemas de Acueductos y Alcantarillados Comunales (ASADAS), figuras utilizadas por empresas hoteleras y desarrollos inmobiliarios opulentos, sin la fijación de un canon o tarifa por su uso y sin el pago de impuestos, ni el consumo por litros por segundo, lo que genera desigualdad en la distribución y competencia desleal hacia las comunidades costeras, que deben pagar las tarifas por el suministro del agua.

En esta gobernanza han de fortalecerse las instituciones y su marco legal, creadas para salvaguardar el recurso hídrico, entre ellas AyA, el Servicio Nacional Aguas Subterráneas Riego y Avenamiento (SENARA) y las ASADAS; asimismo, que estas hagan cumplir la Ley de aguas (1949) y sus reformas (1974 y 1996), en la defensa de las poblaciones costeras, que además deben enfrentar los efectos de las continuas sequías por fenómenos atmosféricos como el Niño y el cambio climático.

Es indispensable contar con una estrategia que compatibilice e integre las necesidades de conservación y protección con las de desarrollo socio económico como elemento de un mismo proceso y que ofrezca opciones para conciliar los intereses particulares con los de la colectividad. De igual manera, aplicado a los planes de manejo, distribución y consumo con un marco de administración, donde el derecho al agua sea equitativo para todas las clases y grupos sociales.

El concepto de Gestión Integrada del Recurso Hídrico se ha modificado y ampliado para incorporar la toma de decisiones participativa, es así que Cap.- NEP, 2005 manifiesta que:

Diferentes grupos de usuarios (agricultores, comunidades, ambientalistas) pueden tener influencia en las estrategias para el desarrollo y la gestión del recurso hídrico. Esto genera beneficios adicionales, como usuarios informados que aplican auto-regulación local con relación a cuestiones tales como conservación del agua y protección de sitios de captación de una 
Lidia Orias-Arguedas. Guidelines for a comprehensive plan on sustainable

management, management and protection of water resources, coastal space in

El Coco, Nicoya Peninsula, Costa Rica

manera mucho más efectiva que la que puede lograrse con regulación y vigilancia centralizadas. (p.7)

Un PGRI deberá concordar y responder a un marco de política de sostenibilidad, restauración y protección, definido según los tratados internacionales, la normativa y legislación institucional vigente, con la participación de las instituciones públicas rectoras en esta materia: el Tribunal Ambiental Administrativo (TAA), el Ministerio de Ambiente Energía (MINAE), como con el gobierno local (Municipalidad) y las organizaciones de la sociedad civil de las comunidades del espacio costero El Coco.

Debe plantearse dentro de un horizonte de tiempo y un marco conceptual suficientemente amplio, que permita proponer el uso de recursos de orden jurídico, tecnológico, humano, de desarrollo institucional en materia hídrica, así como de nuevas prácticas y actitudes por parte de los consumidores de agua en el espacio costero El Coco. Es por ello que un enfoque sistémico, holístico, participativo, multidisciplinario y de largo plazo, asume la ruta de una propuesta que trasciende la participación de la gestión institucional del Estado y busca la participación de las organizaciones comunales que deberían liderar toda gestión y apoyados por el sector empresarial privado para su implementación.

Los conflictos sociales son ineludibles cuando no existe gestión ambiental participativa. Es así que la temática ha pasado de ser de carácter local a regional. A escala local la población civil requiere:

Un modelo de Gestión Ambiental que pretenda tener coherencia y estar bien fundamentado, debe entender que, la clave, reside en reconocer a los distintos actores de la sociedad que tienen que ver con el proceso, respetar (hasta donde sea posible) sus distintos criterios e intereses y propender a comprometerlos en la Gestión" (Universidad de Tolima - Municipalidad de Ibagué, 2002, p.13).

Es fundamental un cambio en la cultura de los usos del recurso hídrico, es por esto que la participación ciudadana es indispensable para crear los espacios de opinión y propuestas.

La participación significa avanzar en la implicación de la ciudadanía en las decisiones y en las actuaciones públicas. Incorporar a la ciudadanía en 
las decisiones sobre la gestión del agua nos hará acertar en éstas y ser más eficaces a la hora de ejecutarlas (Agencia Catalana del Agua, 2008, p.1).

Un concepto en boga es el de gobernabilidad del recurso hídrico, en Costa Rica no existe claridad en el tema ante la escasa aplicación de la Ley de aguas, deficiente administración prospectiva de los actores institucionales públicos, sin políticas claras en la materia.

Echeverría y Cantillo (2013), señalan que la ausencia de la gobernabilidad se debe a la gran cantidad de leyes sectoriales, igualmente, la falta de definición de competencias y potestades han creado un marco jurídico e institucional complejo para la gestión hídrica. Por lo que la ausencia de una única legislación que regule de manera global la protección, extracción, uso, gestión y administración de los recursos hídricos ha generado que más de quince instituciones en Costa Rica posean alguna relación con el agua.

El recurso hídrico comprende la cantidad de agua existente no solo superficial, también de las aguas subterráneas, que son aquellas que se infiltran en el subsuelo y se almacenan en los acuíferos. Estas se extraen por medio de pozos, o brotan a la superficie como manantiales, conocidos también como recurso hidrogeológico.

Resulta fundamental el estudio de los acuíferos. Existe gran cantidad de metodologías para el estudio de la vulnerabilidad intrínseca a la contaminación, entre las más sencillas destaca la metodología GOD, para la generación de mapas de vulnerabilidad de acuíferos como herramientas para la toma de decisiones con relación a la protección, manejo del recursos hídrico y la sostenibilidad. La metodología utiliza la clasificación de tres fases que son: Distancia del agua, Ocurrencia del agua subterránea y Substrato litológico. Se considera vulnerabilidad muy baja si el valor es menor a 0.1 , baja si el valor está entre 0.1 y 0.3 , moderada si está entre 0.3 y 0.5 , alta si está entre 0.5 y 0.7 y extrema si es mayor a 0.7 . Foster et al., 2002 establecen pasar los índices a clases de vulnerabilidad, por ejemplo: Vulnerabilidad extrema cuando el acuífero es rápidamente susceptible a la mayor parte de los contaminantes existentes, en cuanto a la vulnerabilidad alta, el acuífero se halla vulnerable a muchos contaminantes exceptuando aquellos que generalmente son absorbidos o transformados. 
Lidia Orias-Arguedas. Guidelines for a comprehensive plan on sustainable

management, management and protection of water resources, coastal space in

El Coco, Nicoya Peninsula, Costa Rica

\section{Discusión de resultados}

La crisis por la gestión del recurso hídrico, especialmente el subterráneo, es manifiesta en los espacios costeros de la Península de Nicoya. En el espacio costero El Coco, durante el primer decenio del siglo XXI, se produjo una creciente demanda de tierra para la construcción de áreas residenciales, así como la inversión en equipamiento recreativo para sectores de ingresos medios y altos, condiciones que se vieron favorecidas por la desaparición de la producción agropecuaria y la escasa actividad pesquera que una vez determinaron la economía local, cuya subsistencia se presentaba en torno al área costera.

El Coco está incrementando su presión por el recurso hídrico, a causa de los cambios en el uso de la tierra y la inmigración de población de altos ingresos (en su mayoría extranjera), lo que ha dado origen a un acelerado crecimiento urbano, notorio en la construcción de viviendas y condominios, que han configurando el espacio urbano como un archipiélago, con usos tan diferenciados entre las distintas clases y grupos sociales, que forman islas con características propias.

En el espacio costero de El Coco, las necesidades básicas de abastecimiento de agua potable están siendo cubiertas deficientemente, por lo que se está muy cerca de llegar a situaciones de estrés hídrico, es decir, donde resulta muy difícil garantizar la cantidad y calidad de agua suficiente para satisfacer las necesidades domésticas de la población y de las inversiones económicas futuras, que pueden provocar conflictos sociales.

Existe un marcado descontento en los sectores populares con AyA, porque han visto disminuir su disponibilidad del recurso hídrico ante la llegada de nueva población residente y flotante, al tiempo que las tarifas se mantienen altas. De las encuestas realizadas durante el año 2010, en los segmentos de barrios del área de estudio, se corroboró que existía problemas de disponibilidad de agua durante los meses del período seco; asimismo, las tarifas diferían en los distintos barrios. De las 60 encuetas realizadas, 42 entrevistados consideraron que el incremento del turimo provoca problemas en la cantidad de líquido recibido. Un dirigente entrevistado del Barrio San Martín, expuso que sus recibos fluctuaban continuamente sin razón aparente, con montos entre los $\varnothing 15000, \varnothing 70000, \varnothing$ 120 000, para ese año presentaba una deuda de $\varnothing 400000$ al AyA, y debió establecer una demanda a la institución (García, com. pers., 2010). Como 
él existen muchos casos de pagos excesivos, también atribuidos a las constantes fugas de agua.

Al consultarse si los trasvases o nuevas fuentes del recurso hídrico son necesarios para satisfacer la demanda, la mayoría de las respuestas (49) fueron que sí. Esta consulta es muy clara para los encuestados, en tanto eran conocedores del proyecto de Coco - Water para el trasvase de agua de Sardinal al espacio costero El Coco, el cual aun ven como una posibilidad de solucionar la escasez del servicio del servicio de agua potable.

Cinco años después de finalizado el trabajo de campo, la realidad sobre la escasa gestión del recurso hídrico, continúa afectando los pobladores del área de estudio. El diario nacional la Extra (22 Julio, 2015) destaca la noticia: Guanacastecos gritan ¡agua!. Pobladores y empresas exigen acciones para garantizar el vital líquido, en ella se enfatiza la difícil situación de disponibilidad de agua en el espacio costero El Coco:

Al año, Guanacaste desaprovecha hasta 700 millones de metros cúbicos de agua, pues al no contar con suficiente infraestructura como por ejemplo plantas de almacenamiento y de potabilización y acueductos, ocasiona que la mayor cantidad de agua trascurra a montones hacia el océano Pacífico.

José Ramón tiene tres años de vender copos en varias zonas de Playa del Coco, con el fin de garantizarse un ingreso para su familia, y manifestó que en su pueblo, Las Lomas, tienen años no ver el agua potable de manera constante, sino que solo por algunas horas.

Esta situación igualmente fue cosntatada durante el año 2010, cuando presentaban las mismas limitaciones de disponibilidad del agua. Los montos pagados eran desde los $\varnothing 8000$ a los $\varnothing 19000$ mensuales, que a su vez representa un alto porcentaje para el salariado obrero.

Actualmente, AyA y el SENARA, desconocen la cantidad y usos de los pozos ilegales, lo cual resulta a su vez en un desconocimiento del comportamiento de los niveles y flujos del acuífero El Coco, haciéndolo vulnerable a la contaminación química (nitratos) y bacteriológica (coliformes), así como de intrusión salina.

La gestión del recurso hídrico en el espacio costero El Coco, será posible con la participación transversal de los diferentes actores sociales locales e institucionales, a fin de regular el canon, acceso, disponibilidad y calidad del agua, lo cual solucionaría conflictos sociales y políticos. 
Lidia Orias-Arguedas. Guidelines for a comprehensive plan on sustainable

management, management and protection of water resources, coastal space in

El Coco, Nicoya Peninsula, Costa Rica

Surge la necesidad de proteger el recurso hidrogeológico, de lo contrario esto podría afectar no solo la economía local y los ecosistemas, sino también, la mejora del modo de vida de las comunidades, siendo fundamental la salud ambiental y pública.

El costo actual de las concesiones para aprovechamiento de aguas lo establece el Ministerio de Ambiente y Energía (MINAE), que como ente rector controla y regula estos costos; igualmente, creó un canon de pago tanto para concesionarios y usuarios del agua. En el duodécimo informe sobre el Estado de la nación en desarrollo humano sostenible (2006), se indica que la deficiente estructura de cobro y a que dos grandes usuarios como el Instituto Costarricense de Acueductos y Alcantarillados (AyA) y el Instituto Costarricense de Electricidad (ICE), no reconocen este pago por interpretaciones legalistas. El informe del estado de la nación evidencia que:

El canon vigente promulgado en 1998, permitió recaudar para ese año 200 mil dólares y para este año se esperan 327 mil dólares. Esto se da en el marco de una estructura de valor risorio y comportamiento decreciente (a mayor caudal asignado menos pago). Lo anterior, en vez de contribuir a la gestión, se ha reflejado negativamente pues no solo no genera los recursos financieros mínimos para permitir una actividad seria del sector, sino que promueve el desperdicio de las reservas del agua (p.5).

Otro aspecto para discutir es la lógica de la economía de mercado, que se manifiesta en el modelo de "desarrollo" neoliberal (crecimiento económico), deja a la libre el funcionamiento de cadenas hoteleras transnacionales, con una oferta de servicios que responden no sólo a la captura de población fluctuante, en su mayoría turismo extranjero con gran capacidad económica; en correspondencia con la temporada alta durante el período seco y más cálido (de siete meses), donde el consumo de agua se incrementa.

Un factor de gran relevancia es el Fenómeno ENOS, el cual no ha sido un elemento trascendente en la "planificación" de instituciones públicas vinculantes al recurso hídrico, como: SENARA; MINAE o el AyA, aun cuando este es recurrente, basta con enumerar los eventos de los últimos períodos: 1991-1994, 1997-1998, 2002-2003, 2006-2007, 2009-2010 y 2012. El año 2014 presentó la mayor magnitud de intensidad de calentamiento del Pacífico oriental respecto al 1997-1998, con un índice de 
Oscilación del SUR (IOS) atmosférico para el mes de agosto de - 8.8, donde la influencia directa de El Niño produce el déficit de lluvias y la consecuente sequía en la Península de Nicoya, (IMN, 2014). Al mes de mayo de 2015, la intensificación del fenómeno El Niño en el Pacífico ecuatorial, moduló ampliamente los patrones atmosféricos e inhibió el establecimiento de la estación lluviosa en el Pacífico Norte, esta situación provocó déficits de hasta $100 \%$ en el norte de Guanacaste (IMN, 2015).

Debe reflexionarse en la población nativa de bajos ingresos, que ha visto encarecer su capacidad de consumo de agua, debido al aumento en el costo de la vida, que incluye además las altas tarifas del agua.

Se debe proponer un marco de gestión integral donde se regule la oferta ambiental del recurso hídrico, con la demanda ambiental y humana en el contexto costero.

Es a partir de estos principios de referencia y de las condiciones determinantes, que se plantea una propuesta de gestión integral en el manejo sostenible, administración y protección del recurso hídrico, en cuatro componentes. Los cuadros 1, 2, 3 y 4 los describen, utilizando los rangos de vulnerabilidad descritos en el Marco Conceptual, derivados de la metodología GOD (aplicada por Gómez, 2005), correspondientes a extrema y alta vulnerabilidad y se adjuntan los indicadores cualitativos de mayor influencia de vulnerabilidad según el diagnóstico ambiental derivado en la presente investigación. 
Lidia Orias-Arguedas. Guidelines for a comprehensive plan on sustainable

management, management and protection of water resources, coastal space in

El Coco, Nicoya Peninsula, Costa Rica

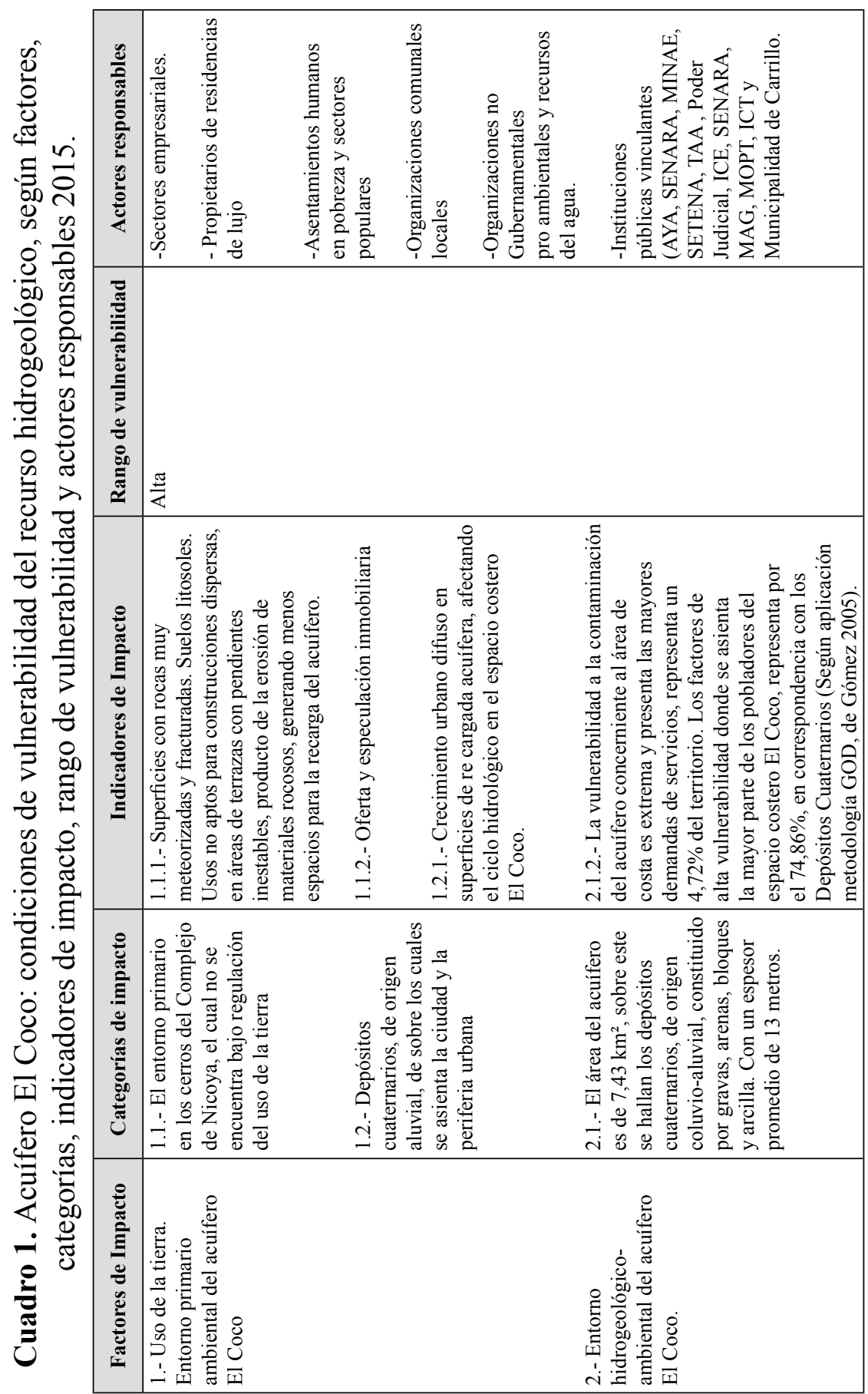

112 Revista Geográfica de América Central No 55 ISSN 1011-484X, julio-diciembre 2015, pp. 95-128 
http://dx.doi.org/10.15359/rgac.2-55.4

Lidia Orias-Arguedas. Lineamientos para un plan de gestión integral en el manejo sostenible, administración y protección del recurso hídrico, en el espacio costero El Coco, Península de Nicoya, Costa Rica

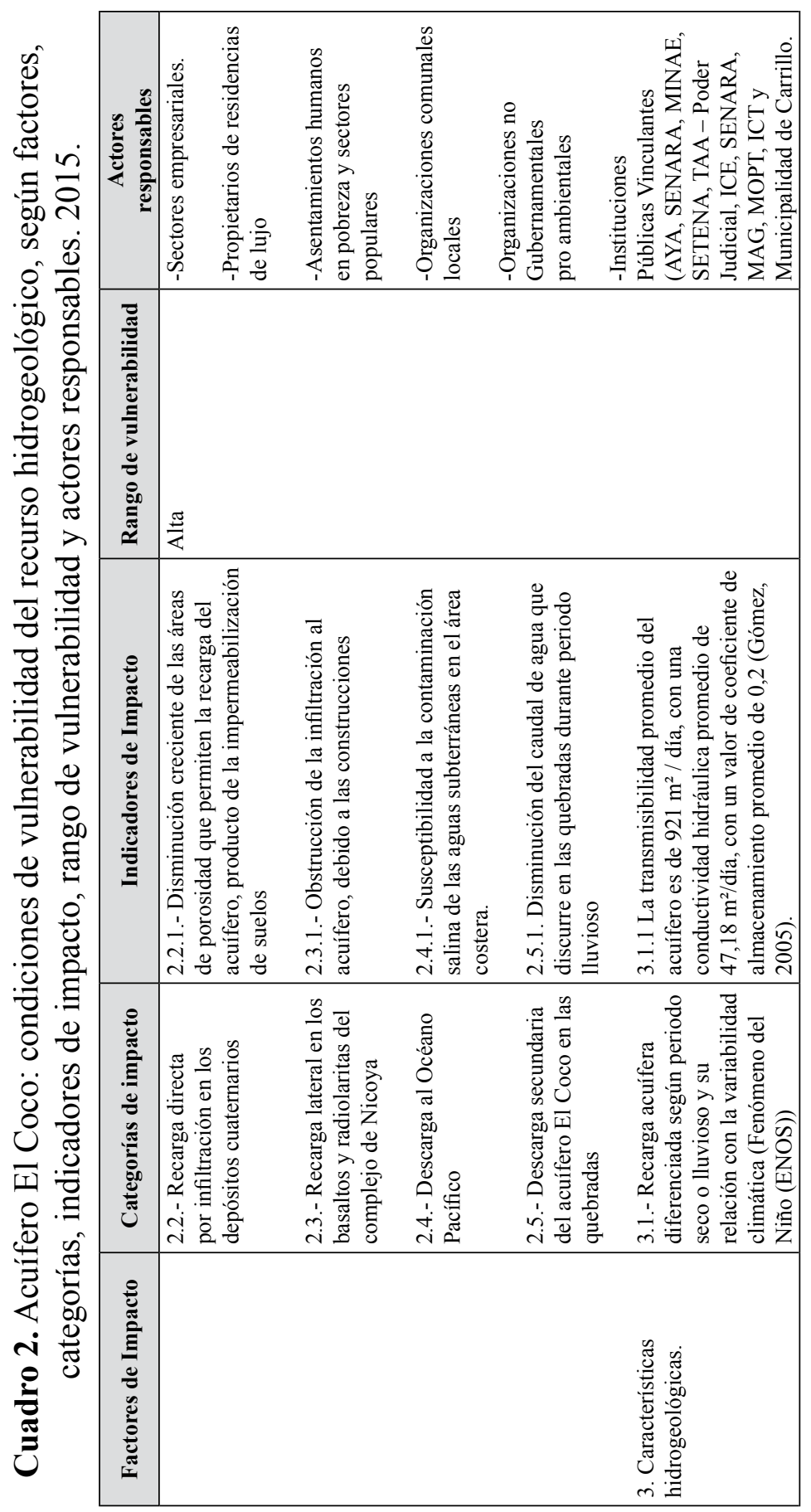


Lidia Orias-Arguedas. Guidelines for a comprehensive plan on sustainable

management, management and protection of water resources, coastal space in

El Coco, Nicoya Peninsula, Costa Rica

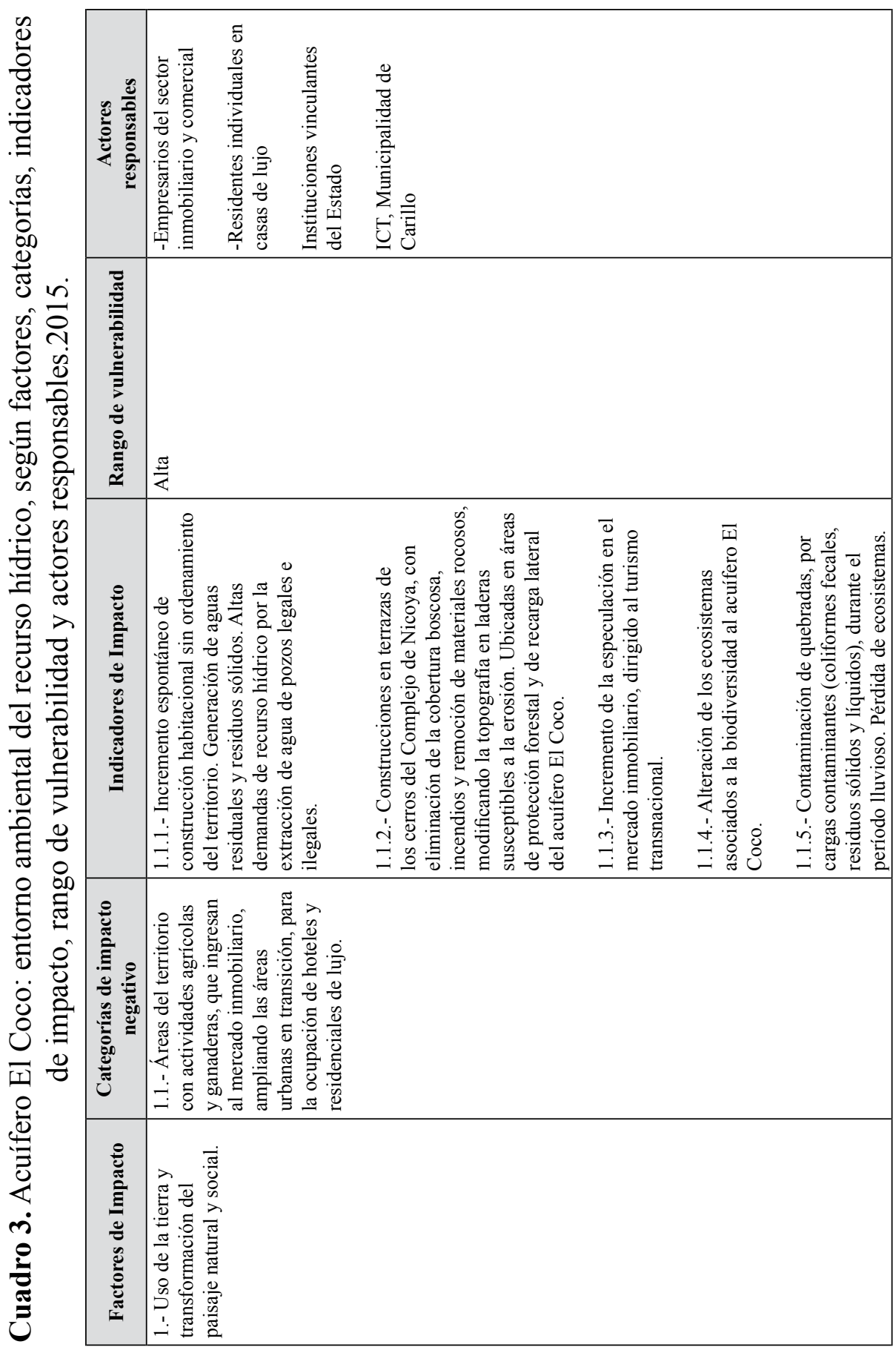

114 Revista Geográfica de América Central No 55 ISSN 1011-484X, julio-diciembre 2015, pp. 95-128 

administración y protección del recurso hídrico, en el espacio costero El Coco, Península de Nicoya, Costa Rica

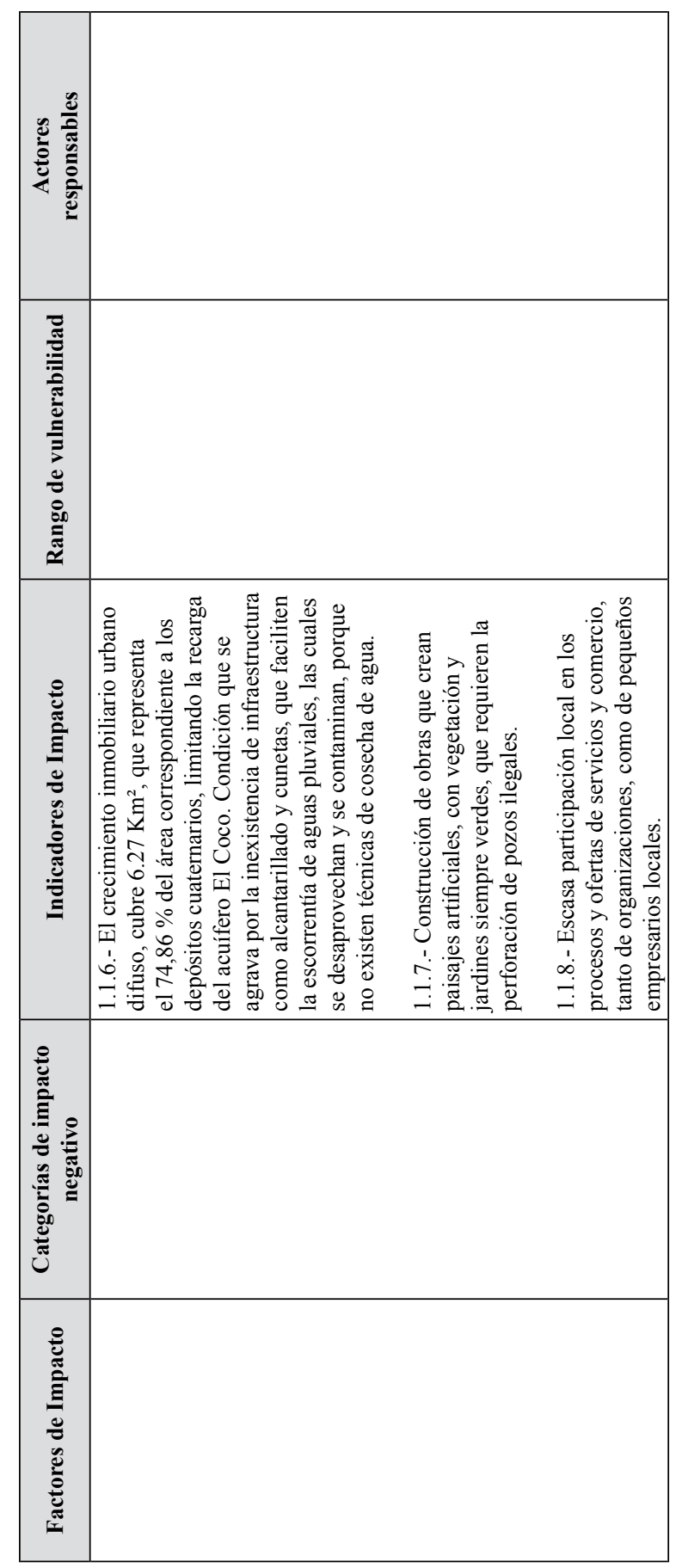


Lidia Orias-Arguedas. Guidelines for a comprehensive plan on sustainable

management, management and protection of water resources, coastal space in

El Coco, Nicoya Peninsula, Costa Rica

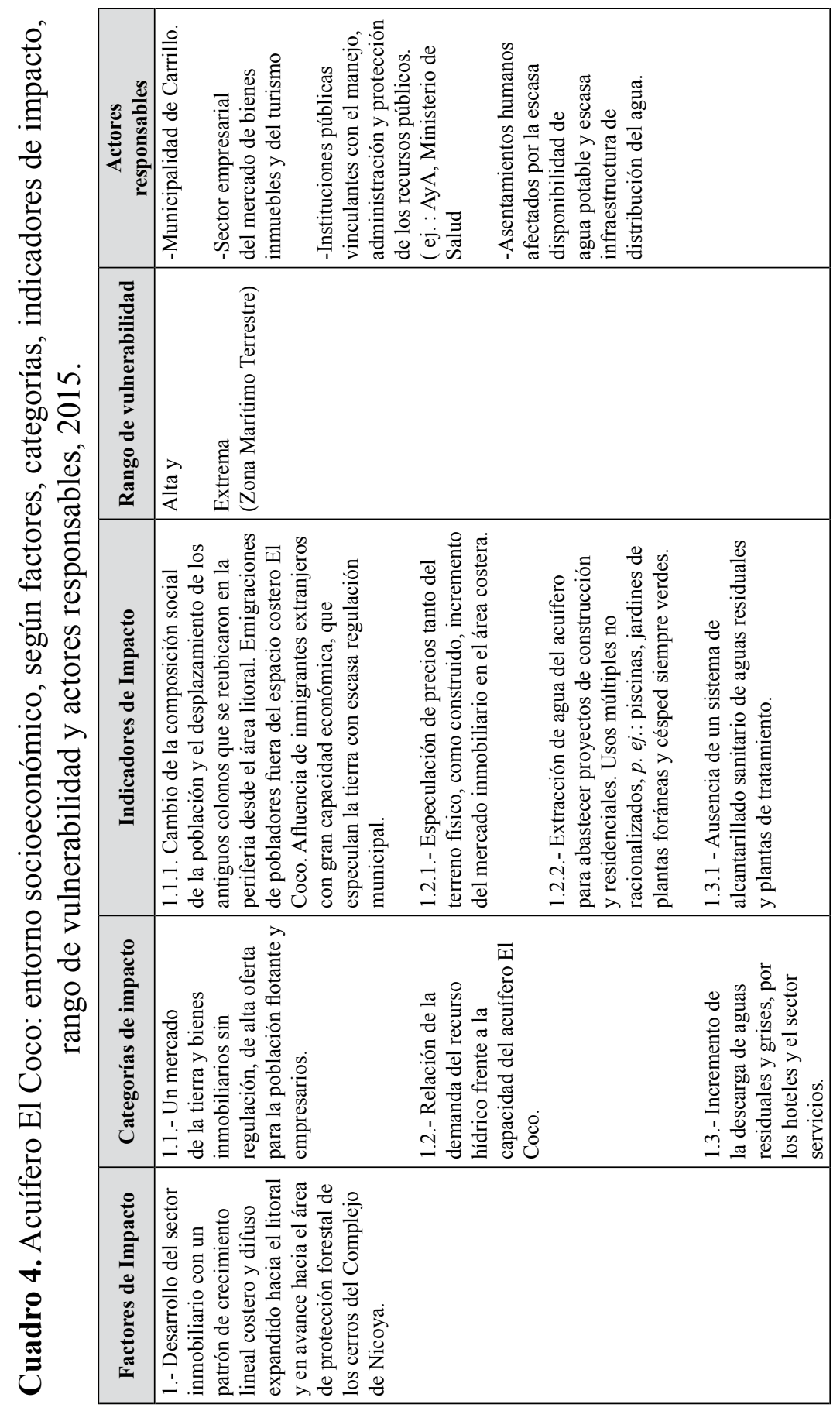

116 Revista Geográfica de América Central No 55 ISSN 1011-484X, julio-diciembre 2015, pp. 95-128 
http://dx.doi.org/10.15359/rgac.2-55.4

Lidia Orias-Arguedas. Lineamientos para un plan de gestión integral en el manejo sostenible, administración y protección del recurso hídrico, en el espacio costero El Coco, Península de Nicoya, Costa Rica

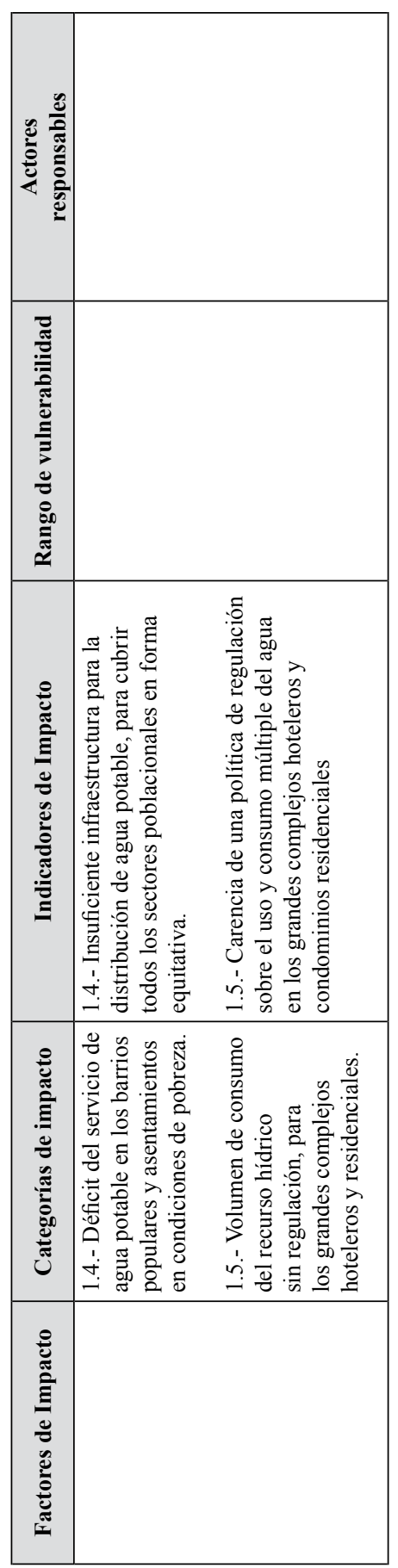


Lidia Orias-Arguedas. Guidelines for a comprehensive plan on sustainable

management, management and protection of water resources, coastal space in

El Coco, Nicoya Peninsula, Costa Rica

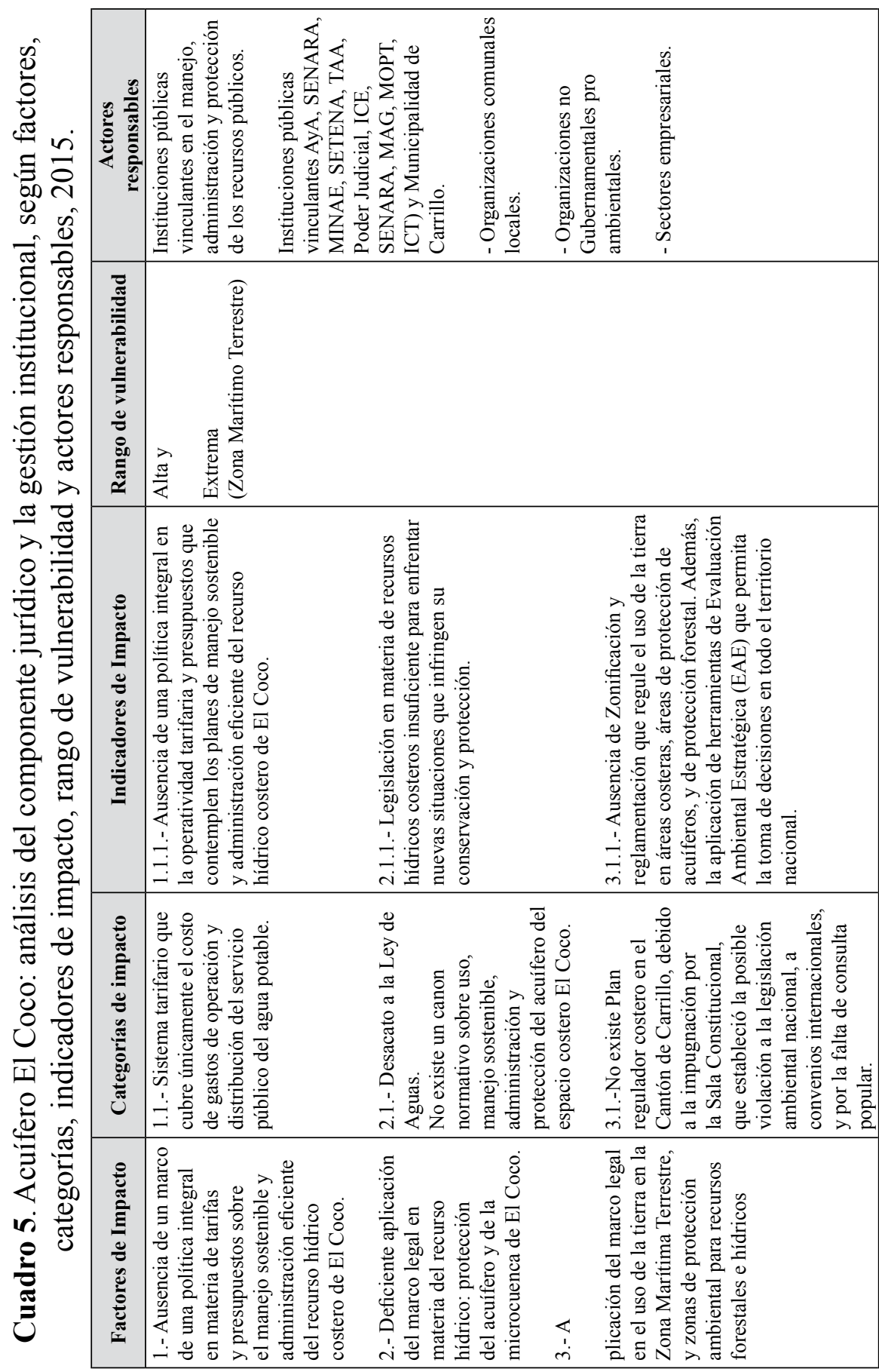



administración y protección del recurso hídrico, en el espacio costero El Coco, Península de Nicoya, Costa Rica

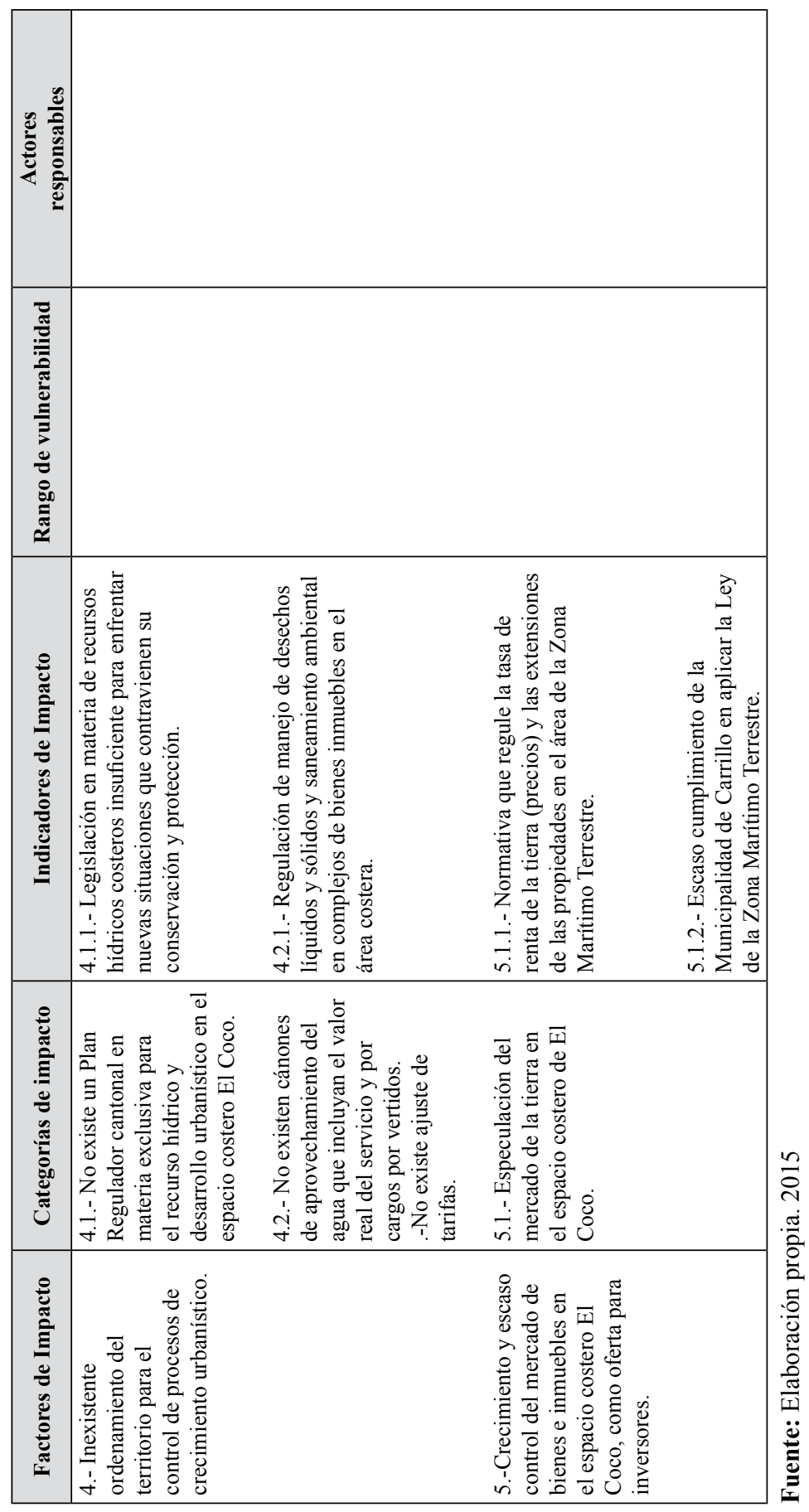


Lidia Orias-Arguedas. Guidelines for a comprehensive plan on sustainable

management, management and protection of water resources, coastal space in

El Coco, Nicoya Peninsula, Costa Rica

\section{PROPUESTA DE PLAN DE GESTIÓN INTEGRAL EN EL MANEJO SOSTENIBLE, ADMINISTRACIÓN Y PROTECCIÓN DEL RECURSO HÍDRICO EN EL ESPACIO URBANO COSTERO EL COCO}

\section{Elementos de un plan de gestión integral del recurso hídrico}

La línea de desarrollo que se ha planteado en este plan, articula cuatro estrategias: 1. conservación, 2. Manejo y administración sostenible del recurso hídrico, 3. prohibición - restauración de recursos de áreas críticas en el entorno primario del acuífero El Coco y 4. estrategia de revisión reforma del marco jurídico en materia de los recursos hídricos costeros.

Como plan de gestión integral del recurso hídrico, debe definirse una estrategia de intervención, asumiendo los factores de extrema y alta vulnerabilidad a la contaminación del acuífero El Coco, en consideración a metodología GOD (ya aplicada (por Gómez, 2005). La intervención dependerá de los recursos institucionales de los entes rectores en esta materia, incluyendo el TAA y la Municipalidad de Carrillo.

Un elemento importante en toda estrategia, son las condiciones de viabilidad tanto institucional, como técnica y social. Desde este punto de vista, se recomienda iniciar con la estrategia de conservación, estableciendo una zonificación de protección, restauración, amortiguamiento y usos restrictivos de la tierra aún no ocupada en el entorno primario y su ambiente, con relación al acuífero El Coco.

En segundo lugar, corresponde a la estrategia de prohibición - restauración en las áreas críticas de alta vulnerabilidad y extrema vulnerabilidad de las afectaciones del recurso hídrico en el espacio costero El Coco; en este contexto, se establece que las responsabilidades correspondientes sean administrativas o penales.

En tercer lugar, se asume una estrategia del papel del agua en el desarrollo socio económico local. Lo que relaciona el servicio público del agua en forma equitativa sin excluir a los sectores populares y en pobreza; asimismo, de los problemas de calidad de los servicios entre los que se mencionan la red de distribución, la cantidad de agua utilizada y el uso racional - sostenible, además de un canon de costos administrativos para su sostenibilidad institucional, entre otros. Lo anterior considera una alta relevancia política y social por la regulación de los conflictos por el recurso hídrico. 
Las tres estrategias serán abordadas en el denominado Programa I.

La cuarta estrategia (Programa II) corresponderá a un proyecto de reforma de ley en materia de recursos hídricos en áreas costeras; que por el ingreso de las grandes inversiones del turismo establecen la necesidad no sólo de revisar el marco legislativo existente y su pertinencia, y aplicación en estas nuevas condiciones de crecimiento económico - social de servicios; sino y mayormente por los impactos negativos acumulados al recurso hídrico. Se trata de una estrategia donde se relaciona el marco jurídico en esta materia y las competencias de gestión institucional de carácter obligatorio, generando una nueva cultura jurídica - institucional de rendición de cuentas en la protección, sostenibilidad y conservación del recurso hídrico en el espacio costero El Coco.

\section{PROGRAMA I \\ MANEJO SOSTENIBLE, SISTEMAS DE CONTROL Y GESTIÓN ADMINISTRATIVA DEL RECURSO HÍDRICO DEL ESPACIO URBANO COSTERO EL COCO}

\section{Directriz o lineamiento central}

a. Establecimiento de la conservación del recurso hídrico a partir de una zonificación de protección, restauración, amortiguamiento y usos prohibidos del suelo aún no ocupados en el entorno primario y su ambiente.

b. Instituir los cánones de prohibición - restauración en las áreas críticas de alta vulnerabilidad y extrema vulnerabilidad de las afectaciones del recurso hídrico en El Coco; según se establecen las responsabilidades administrativas o penales de los responsables.

c. Elaboración de un marco de política sobre la importancia del agua en el desarrollo socio económico local, donde se establezcan relaciones en los servicios de utilidad pública asociados al agua en forma equitativa, que garantice la distribución, la cantidad y calidad de agua utilizada y el uso racional - sostenible, además de un canon de costos administrativos de su sostenibilidad institucional, entre otros. Lo anterior toma alta relevancia política y social por la regulación de los conflictos por el recurso hídrico. 
Lidia Orias-Arguedas. Guidelines for a comprehensive plan on sustainable

management, management and protection of water resources, coastal space in

El Coco, Nicoya Peninsula, Costa Rica

\section{Despliegue de medidas según la estrategia uno, dos y tres - po- sibles proyectos}

1. Implementación de un plan de manejo sostenible de rescate y restauración de los entornos primarios críticos de la superficie (áreas de extrema y Alta vulnerabilidad), y que son vitales para la recarga del acuífero. Incluye acciones de reforestación de especies nativas hasta la reubicación de propietarios según lo establezca el marco de la legislación ambiental y de protección de los recursos hídricos del espacio costero El Coco.

2. Formalizar según los límites territoriales que establece la legislación ambiental y de protección del recurso hídrico, las zonas de amortiguamiento, de Protección perimetral de pozo (PPP), así como la determinación de las Zonas de captura o de carga del pozos (ZOC), del acuífero El Coco.

3. Implementar en forma permanente monitoreos piezométricos y de calidad de aguas en las áreas de mayor vulnerabilidad y densidad de pozos, con el fin de mantener sitios de monitoreo hidrogeológico y establecer medidas de protección contra la contaminación y el deterioro de la calidad del agua subterránea y superficial.

4. Realizar un estudio de la demanda actual del agua subterránea diferenciando los períodos secos y lluviosos, los efectos del fenómeno ENOS y su relación con la variabilidad climática y el incremento de los flujos migratorios de población fluctuante o flotante (turistas) en el espacio costero El Coco.

5. A partir de los estudios especializados de la oferta del acuífero, los entornos o áreas críticas, el monitoreo en calidad y niveles piezométricos y los usos múltiples de la demanda, elaborar un marco de política de aprovechamiento sostenible, ordenamiento de las extracciones (pozos) y la administración racional (regulada), que permita que el recurso hídrico llegue a todos los sectores y grupos poblacionales.

6. EL Plan deberá permitir la elaboración de una regulación de la apertura, extracción y forma de uso de los pozos entre otros temas.

7. Implementar una evaluación sobre el estado de la infraestructura de distribución de agua potable e invertir para su ampliación a las comunidades que presentan problemas de disponibilidad. 
8. Proponer planes de manejo con técnicas de tratamiento para la reutilización o reciclaje de aguas grises y pluviales o de fuentes complementarias superficiales. Con el fin de disminuir los volúmenes de consumo de agua potable, en actividades como el riego de los jardines en los complejos hoteleros o condominios, la limpieza, el lavado de autos entre otros.

9. Elaborar un marco administrativo sobre tarifas y presupuestos para el manejo sostenible y eficiente del recurso hidrogeológico.

\section{PROGRAMA II \\ IMPULSAR UN PROYECTO QUE PERMITA LA REFORMA DE LA LEGISLACIÓN EN MATERIA DEL RECURSO HÍDRICO EN ESPACIOS COSTEROS Y LA GESTIÓN INSTITUCIONAL PÚBLICA}

\section{Directriz o lineamiento central}

Que los actores sociales, empresarios locales, instituciones públicas y el gobierno local propongan un proyecto de Reforma de ley en materia de recursos hídricos para espacios costeras; con el fin de revisar el marco legislativo existente, su pertinencia y aplicación en estas nuevas condiciones de crecimiento económico - social; además por los impactos negativos acumulados sobre el recurso hídrico. Se trata de articular el marco jurídico en esta materia y las competencias de gestión institucional de carácter obligatorio, generando una nueva cultura jurídica - institucional de rendición de cuentas tanto en la protección, sostenibilidad y conservación del recurso hidrogeológico en el espacio urbano costero El Coco.

\section{Despliegue de medidas del programa (acciones) - posibles proyectos}

1. Impulsar un proyecto de ley (reforma) en materia de manejo sostenible, administración y protección de los recursos hídricos; que permitan enfrentar los cambios actuales y conflictos que están generando las nuevas formas de crecimiento económico, principalmente, en los espacios costeros de Costa Rica, donde se garantice el papel estratégico del agua para el desarrollo local. 
Lidia Orias-Arguedas. Guidelines for a comprehensive plan on sustainable

management, management and protection of water resources, coastal space in

El Coco, Nicoya Peninsula, Costa Rica

2. Que el TAA, junto a SETENA, el MINAE y SENARA, realicen un estudio de la condición legal de las propiedades que se encuentran localizadas sobre las áreas de recarga del acuífero, y se tomen las medidas administrativas y judiciales según corresponda con la aplicación de la legislación.

3. La elaboración por parte de la Municipalidad de Carrillo de un plan de ordenamiento del territorio donde se establezcan los usos restringidos y permitidos de la zonificación y se establezcan los límites territoriales de protección del área del acuífero El Coco. El Plan de ordenamiento será vinculante al Plan Regulador del cantón de Carrillo, donde se consideren las áreas de extrema y alta vulnerabilidad y la de moderada vulnerabilidad del acuífero El Coco, para dirigir el futuro ordenamiento del territorio.

4. Abrir espacios y procesos de concertación, participación y responsabilidad compartida por parte de todos los actores sociales, gobierno local, empresas locales e instituciones públicas considerando sus diversas competencias administrativas y jurídicas en materia del recurso hídrico; y de la asignación de los derechos y obligaciones a los distintos usuarios del recurso.

5. Que el Ministerio de Salud, en unión con AyA y SENARA realicen un estudio en las propiedades para determinar el número, caudal, niveles piezométricos, calidad y condición legal de los pozos (como mínimo han de realizarse muestreos); con el fin de establecer las medidas administrativas correctivas y restauradoras correspondientes a la legislación.

\section{Conclusiones}

- El marco jurídico existente en el manejo (usos), distribución, administración y protección del recurso hídrico es aplicado de manera insuficiente a nivel institucional, en el espacio costero El Coco. Con ello se indica la utilización de leyes con traslape de acciones administrativas de las instituciones públicas; que no responden a las nuevas exigencias y desafíos que implican las tendencias de crecimiento económico costero, que generan impactos ambientales negativos en el recurso hídrico en su cantidad y calidad, sostenibilidad y protección. 
- El discurso y prácticas legales se materializan en una cultura institucional ineficaz tanto en las competencias administrativas (SENARA, AyA, Ministerio de Salud y otros), como judiciales (TAA, SETENA, y otros), esto en la organización de un modelo político del Estado que no posee un modelo integral de gestión del recurso hídrico en espacios costeros como El Coco.

- $\quad$ El ICT no ha sido coherente en su responsabilidad de hacer cumplir la Ley de la Zona Marítima Terrestre, en tanto le corresponde el ordenamiento costero y litoral, pero se evidencian incompatibilidades al impulsar y promocionar actividades turísticas de carácter transnacional e ilegal en zona pública, que afectan directamente al acuífero de El Coco.

- Al considerar la forma irracional de uso del recurso hídrico en el espacio costero El Coco, se demuestra un gran vacío respecto a las políticas públicas integrales de sostenibilidad.

- Cuando se denuncian deficiencias en el uso de la tierra y sus repercusiones sobre el acuífero El Coco e incluso se plantean recursos de amparo ante la Sala Constitucional, se inician discusiones entre los diversos actores sociales, donde los representantes institucionales atribuyen estos problemas a la carencia de un Plan Regulador urbano aprobado por el INVU, el cual es imprescindible; sin embargo, aún sin su existencia, si se cumpliese la legislación existente, que implica los componentes socio ambientales, urbanos, salud y de conservación, no se estaría a las puertas de un estrés hídrico, en el que algunos sectores sociales excluidos presagian la expulsión definitiva de su entorno.

- Aún con las resoluciones de la Sala Cuarta, que prohíbe la apertura de nuevos pozos y la extracción continúa sin control, las entidades locales: la Municipalidad de Carrillo y AyA, no han atendido su rol referente al cumplimiento de esta disposición, en tanto que los desarrolladores privados han descubierto nuevas estrategias para obtener el agua, desafiando las leyes de protección ambiental. Se demuestra que la administración pública, tanto municipal como nacional han actuado con escasa coordinación.

- La Municipalidad de Carrillo tiene un compromiso con su comunidad en la construcción obras de infraestructura urgentes como el alcantarillado pluvial y servicios básicos; además, porque El Coco 
Lidia Orias-Arguedas. Guidelines for a comprehensive plan on sustainable

management, management and protection of water resources, coastal space in

El Coco, Nicoya Peninsula, Costa Rica

presenta una de las costas más urbanizadas y ocupadas por el turismo transnacional y nacional en la Península de Nicoya.

- $\quad$ Se insiste en un Plan de gestión del recurso hídrico de manera integral, con visión a largo plazo, sostenible y que plantee una dirección de desarrollo económico - ambiental equilibrado con todos los sectores: empresariales, instituciones públicas vinculantes con el manejo, administración y protección del recursos hídrico, a fin de hacer cumplir el amplio marco legal existente; paradójicamente, en Costa Rica se ha generado la aparición de propuestas para cambiar la legislación, como la Ley de Aguas que rige desde el año 1942 y modificada en 1996. Se han debatido en la Asamblea Legislativa nuevas propuestas, como el Proyecto de Ley para la Gestión Integrada del Recurso Hídrico (17 de setiembre 2009), la cual presentó contradicciones en su texto y más de 100 artículos, que dio lugar a su constante revisión y diferencias e intereses políticos, también desde los sectores económicos y sociales. Toda esta situación desvía la atención, pues la Ley de Aguas no es el problema sino la ineficaz gestión del recurso hídrico, lo verdaderamente importante es que el agua es un derecho humano y no un bien económico.

\section{Referencias}

Agencia Catalana del Agua (2009). Planes de gestión de cuencas. Plan de gestión del distrito de cuenca fluvial en Cataluña. Recuperado de: http://mediambient.gencat.net/aca/es/inici.jsp.

Asamblea Legislativa. (1942). Ley de Aguas № 276. San José, Costa Rica. Asamblea Legislativa. (1977). Ley sobre de Zona Marítima Terrestre $\mathrm{N}^{\circ}$ 604. San José, Costa Rica.

Asamblea Legislativa. (2002). Proyecto de Ley del Recurso Hídrico- texto sustitutivo, Expediente No 14.585. San José, Costa Rica.

Astorga, Y. (2006). Duodécimo informe sobre el Estado de la Nación en Desarrollo Humano. Costa Rica, ONU - PNUD.

Cap.- NEP. (2005). Planes de Gestión Integrada del Recurso Hídrico. Manual de Capacitación y Guía Operacional.

Centro de Derecho Ambiental y de los Recursos Ambientales (2001). La Gestión Integral del Recurso Hídrico. Manual de Regulaciones 
Jurídicas para la Gestión del Recursos Hídrico en Costa Rica. San José, Costa Rica.

Dourojeanni, A. (1993). Procedimientos de Gestión para un Desarrollo Sustentable. CEPAL, Santiago.

Echeverría, J. y Cantillo, B. (2013). Instrumentos económicos para la gestión del agua. En: Revista Ambientales, 45.

EL País, (2014). Sala IV paraliza plan regulador costero de Carrillo por irregularidades. Recuperado de: http://revista-amauta.org/2013/08/ sala-iv-ley-de-territorios-costeros-es-inconstitucional/

Gómez, M. (2005). Estudio Hidrogeológico Integral de La Cuenca Hidrográfica de los poblados El Coco y Ocotal, Carrillo, Guanacaste. Tesis para optar el grado de Maestría Académica en Hidrogeología y Manejo de Recursos Hídricos. Universidad de Costa Rica. San José, Costa Rica.

IV Foro Mundial del Agua. (2012). Agenda del Agua de Las Américas: Metas, soluciones y rutas para mejorar la gestión de los recursos hídricos. Recuperado de:http://api.ning.com/files/4MPkcj7R26KOU2H8hfTt1E7Med4cbVwswnYn7RAyB3N58njAZz4HcEK93 vbT4Vy7WbX7wdAE2zrP244g1tjOaHDQH7snyKij/AgendadelAguadelasAmricas.pdf

Foster S., Hirata R, Gomes D., D’ Elia, M. y Paris, M. (2002). Guía para empresas de agua, autoridades municipales y agencias ambientales. The World Banc. Washington, D.C.

Instituto de Acueductos y Alcantarillados (AyA). (2008). Informe del estudio especial realizado en el Instituto Costarricense de Acueductos y Alcantarillados, en relación con el desarrollo de los proyectos de los acueductos Sardinal y El Coco-Ocotal. San José.

Instituto de Acueductos y Alcantarillados (AyA). (2012). Calidad Sanitaria de las Aguas de Playa Costa Rica Periodo 1996 - 2011. San José.

Instituto de Acueductos y Alcantarillados (AyA). (2012). Memoria Anual 2011 - 2012. San José. Costa Rica.

Instituto Geográfico Nacional. (1965): Hoja topográfica Carrillo Norte, Guanacaste, Costa Rica (1: 50 000). San José, Costa Rica.

Instituto Nacional de Vivienda y Urbanismo. (2007). Manual de procedimientos para la redacción y elaboración de planes reguladores. Dirección de Urbanismo. San José.,Costa Rica. 
Lidia Orias-Arguedas. Guidelines for a comprehensive plan on sustainable

management, management and protection of water resources, coastal space in

El Coco, Nicoya Peninsula, Costa Rica

Instituto Meteorológico Nacional. (2014). Boletín del ENOS $N^{\circ} 70$. Fase actual: El Niño.San José, Costa Rica.

Instituto Meteorológico Nacional. (2015). Boletín Resumen Meteorológico mensual: mayo 2015. San José, Costa Rica.

La Nación Contaminación fecal amenaza el turismo en Playas del Coco (2013, 13 de julio). Recuperado de: http:/www.nacion.com/nacional/ Contaminacion-amenazael-turismo-Playas-Coco_0_1353464668.html. Guanacastecos gritan jagua!. Pobladores y empresas exigen acciones para garantizar el vital líquido (2015, 21 de julio). La Extra. Recuperado de: http://www.diarioextra.com/Noticia/detalle/265041/ guanacastecos-gritan-agua-

Ministerio de Ambiente y Energía. (2006). Procedimiento técnico para la introducción.de la variable ambiental en los planes reguladores u otra planificación de uso del suelo. Dectreto Ejecutivo No 32967-MINAE. San José, Costa Rica.

Programa Estado de la Nación. (2006). Duodécimo Informe Estado de la Nación en Desarrollo Humano Sostenible. San José, Programa Estado de la Nación.

Sala Constitucional de la Corte Suprema de Justicia. (2009). Res. № 200900262. Exp.: 08-05154-0007-CO. San José, Costa Rica.

Servicio Nacional Aguas Subterráneas y Riego. (2008). Revisión de documentos estudio hidrogeológico de Acuífero Sardinal e informe proyecto final Playas del Coco-Ocotal. San José, Costa Rica.

Universidad del Tolima y Municipalidad Ibagué (2002). Gestión sostenible del agua en la Cuenca hidrográfica del Río Combeima. Módulo 6.

Vargas, E. (2006). Informe proyecto final playas de El Coco - Ocotal, Guanacaste.- 36 págs. AyA. San José, Costa Rica.

WWAP, DHI Water Policy, PNUMA-DH Centro para el Agua y el Medio Ambiente. (2009). Integrated Water Resources Management in Action.

\section{Entrevista abierta}

CASTRO, J.F., 2010.Com. pers. 